\title{
ANÁLISE E VISUALIZAÇÃO DE FORMAS QUADRÁTICAS NA DETERMINAÇÃO DE PONTOS EXTREMANTES
}

\section{KNOWLEDGE ABOUT TEACHING PROFESSIONAL DEVELOPMENT IN THE EARLY YEARS OF LEARNING IN MATHEMATICS STUDENTS}

\author{
Francisco Regis Vieira Alves* \\ Instituto Federal de Educação, Ciência e Tecnologia do Ceará $(*)$ \\ Departamento de Matemática \\ E-mail: fregis@ifce.edu.br
}

\begin{abstract}
Resumo
Enfatizam-se, neste artigo, situações que envolvam a visualização e a análise gráfico-geométrica da noção da forma quadrática hessiana. Tal noção está intimamente vinculada à descrição e identificação de pontos extremantes, para funções do tipo $z=f(x, y)$. Assim, com o uso de uma formulação matemática (polinômio de Taylor de $2 \underline{a}$ ordem) que permite a investigação de tais pontos, acrescenta-se o uso dos softwares Geogebra e do CAS Maple, a fim de envidar os esforços didáticos no sentido de uma significação intuitiva e heurística de situações particulares, no contexto do ensino do Cálculo a Várias Variáveis - CVV. Pontuando a descrição sugerida por Lima (2009), no contexto de Análise no $I R^{n}$, apresentam-se outros padrões gráfico-geométricos concernentes ainda ao mesmo critério de investigação. As situações discutidas buscam suavizar as rotinas algoritimizadas e invariantes do ensino acadêmico. Ademais, determinadas limitações dos softwares podem ser superadas, quando apoiadas em um ambiente de uso didático, de maneira complementar.
\end{abstract}

Palavras-chave: visualização; forma quadrática hessiana; ensino; tecnologia

\begin{abstract}
We emphasize in this article some situations involving the visualization and a graphic-geometrical analysis of a Hessian quadratic form. This notion is closely linked to the description and identification of extrem points to a kind of functions $z=f(x, y)$. Thus, with the use of a mathematical formulation (Taylot polynomial of 2 nd order), which allows to the investigation of such points is added by the using the CAS Maple and the software GeoGebra, with the intention to make learning efforts towards an intuitive significance and heuristic particular situations, in the teaching context of Calculus in Several Variables - CVV. By the description suggested by Lima (2009) in the context of Analysis teaching $I R^{n}$, we also present some geometric patterns of graphs concerning the same investigation's criterion. These situations discussed here can become lesse important onle some algoritimized routines and invariant academic approach. Moreover, certains limitations of these softwares can be overcome when we explore in such environment of didactic use of complementary manner.
\end{abstract}

Keywords: visualization, quadratic forms, teaching, technology 


\section{INTRODUÇÃO}

Tikhomirov (1990, p. 151) recorda que Fermat extraiu a partir de certos princípios da ótica, noções que envolvem a identificação de pontos extremos. Nesse sentido, "Fermat realmente teve a sua disposição um algoritmo para encontrar máximos e mínimos de funções que era equivalente a estabelecer sua derivada igual a zero.". Outros matemáticos, de tradição em Álgebra, como no caso de Tartaglia, são lembrados por formularem problemas que envolvem a descrição de extremos (TIKHOMIROV, 1990, p. 37). A contribuição, no que concerne ao empenho na busca pela solução de problemas com tal temática, de outras figuras emblemáticas do passado, é discutida por Tikhomirov (1990) desde Heron, Euclides e, até Newton, Daniel Bernoulli e outros.

Hodiernamente, deparamos uma hierarquização em Análise no $I R^{n}$, que vincula a noção de ponto crítico não degenerado com a identificação de extremos e pontos de sela. Cabe recordar que um ponto crítico não-degenerado ocorre quando a matriz hessiana, nesse ponto, é invertível (LIMA, 2009, p. 156). Na figura 1, patenteamos o expediente adotado por Lima (2009) no sentido de significar/distinguir o comportamento padrão das curvas de nível, na vizinhança de um ponto crítico não-degenerado. O que há de inesperado nos desenhos sugeridos por esse autor, diz respeito ao motivo ou argumentação formal que conduzam o leitor a uma sensação de convencimento, quanto a tal comportamento (sem o apelo a teoremas mais profundos em Análise). Podemos esperar, pois, o mesmo padrão gráfico-geométrico nas vizinhanças de um ponto crítico degenerado (onde teremos a matriz hessiana nula)? Ocorrem ainda outros padrões? Como descrever uma classificação mais ampla, seguindo uma intenção didática que se aproxima da perspectiva que encontramos em Lima (2009)? Como relacionar esses padrões com as formas quadráticas associadas à matriz hessiana? Tencionamos responder parte desses questionamentos ao decorrer desses escrito. 


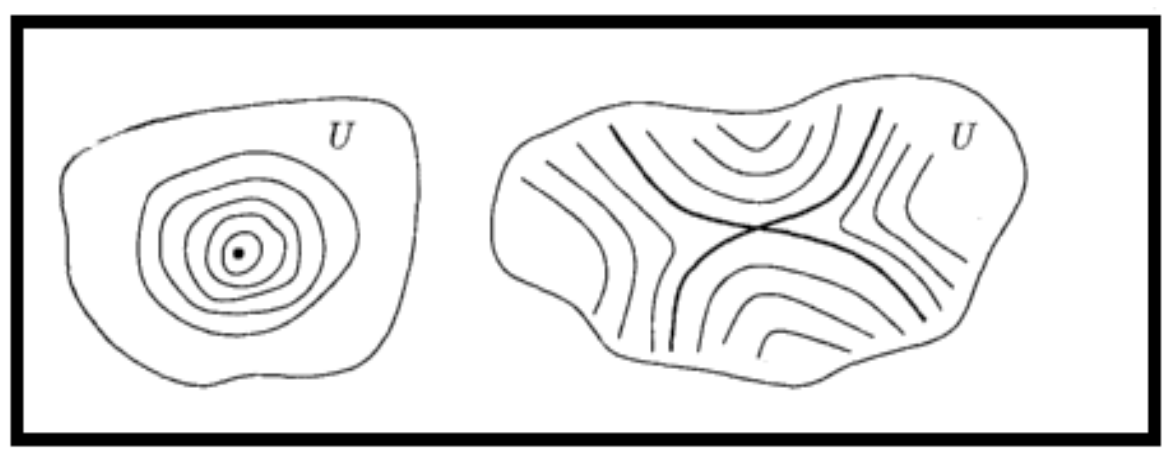

Figura 1. Descrição heurística indicada por Lima (2009, p. 287) das curvas de nível na vizinhança de um ponto crítico não degenerado

Lima (2009, p. 287) explica que o padrão correspondente ao desenho ao lado esquerdo, refere-se a um ponto (não-degenerado) de máximo ou mínimo; enquanto que, o padrão correspondente ao desenho ao lado direito, diz respeito a um ponto (não-degenerado) de sela. O raciocínio envolvido na figura 1 poderia ser utilizado no contexto do ensino do Cálculo, dispensando o formalismo canônico da Análise no $I R^{n}$.

Quando nos atemos, porém, aos livros de Cálculo a Várias Variáveis - CVV. Deparamos um teorema discutido nesses compêndios, originalmente atribuído a Lagrange (1759) (HAIRER \& WANNER, 2008, p. 323-324) e que permite relacionar a noção de ponto crítico não-degenerado com a forma hessiana (LIMA, 2009, p. 157). Na demonstração do mesmo, quando recorremos a uma breve inspeção da literatura, distinguimos duas ideias centrais que estruturam sua demonstração: (i) o uso da derivada direcional de 2a a ordem para sua classificação (GUIDORIZZI, 2010; PINTO; DIOMARA \& MORGADO, 2009; SWOKOWSKI,1983; STEWART, 2004); (ii) o estudo da forma quadrática associada à matriz hessiana (BORTOLOSSI, 2008; KAPLAN, 1993; MARSDEM \& TROMBA, 1991; WIDER, 1947) quando usamos a expansão do polinômio de Taylor até 2a ordem, na vizinhança de um ponto crítico $p \in D_{f}$ (domínio de $f$ ).

Nesse artigo, daremos ênfase, tendo em vista a deficiência nos compêndios de Cálculo, ao método de descrição de pontos extremantes, por meio do estudo das formas quadráticas. O caráter geométrico-gráfico será colocado em destaque, de modo recorrente, na medida em que empregamos as potencialidades dos softwares Geogebra e do CAS Maple, em caráter de 
complementaridade, tendo em vista uma mediação didática direcionada ao ensino do Cálculo (ALVES, 2013, p. 54).

\section{O POLINÔMIO DE TAYLOR E AS FORMAS QUADRÁTICAS}

Nessa seção, consideraremos uma função $f: D_{f} \subset I R^{n} \rightarrow I R$, com $f \in C^{2}$ e um ponto $p \in \operatorname{Int}(D)$ (um ponto interior). Então, é conhecida a seguinte expansão $f(x)=f(p)+D f(p) \cdot(x-p)+\frac{1}{2} \cdot(x-p)^{T} \cdot D^{2} f(p) \cdot(x-p)+R_{2}(p, x)$. Reparemos que $p_{2}(x)$ polinômio de Taylor de $\mathrm{f}$ no ponto $\mathrm{x}=\mathrm{p}$

codificamos a mesma com o uso de matrizes. Em nosso caso, nos interessamos pelos pontos críticos, assim, teremos que $\nabla f(p)=[\partial f / \partial x(p) \partial f / \partial y(p)]=\left[\begin{array}{ll}0 & 0\end{array}\right]$, segue que: $f(x)=f(p)+\frac{1}{2} \cdot(x-p)^{T} \cdot D^{2} f(p) \cdot(x-p)+R_{2}(p, x), \quad$ onde $\quad R_{2}(p, x)=f(x)-p_{2}(x)$ designa o erro que se comete, quando tentamos aproximar a função $f(x)$ do polinômio de Taylor de $f$ em torno do ponto $x=p$ e satisfaz $\lim _{x \rightarrow p} \frac{R_{2}(p, x)}{\|x-p\|^{2}}=\lim _{x \rightarrow p} \frac{f(x)-p_{2}(x)}{\|x-p\|^{2}}=0$.

Bortolossi (2009, p. 383) apresenta uma argumentação capaz de convencer o leitor, sobre a relação entre o comportamento de um ponto $p$ ser um extremo local de $f$ com base na análise do sinal assumido pela expressão $\frac{1}{2} \cdot h^{T} \cdot D^{2} f(p) \cdot h$, onde $h=(x-p)$ é um deslocamento em relação ao ponto. Omitiremos as ideias que envolvem tal demonstração e, a mesma, pode ser consultada ainda em outros autores como Kaplan (1993) e Wider (1947), por exemplo.

Dada agora uma matriz $A_{n \times n}$, com entradas reais, a forma quadrática associada à matriz $A_{n \times n}$ é uma função escalar $Q: I R^{n} \rightarrow I R$, dada por $Q(h)=h^{T} \cdot A \cdot h$, ou ainda, de modo pormenorizado, indica-se $\left(^{*}\right) Q\left(h_{1}, \ldots, h_{n}\right)=\left[\begin{array}{lll}h_{1} & \cdots & h_{n}\end{array}\right] \cdot\left(\begin{array}{ccc}a_{11} & \ldots & a_{1 n} \\ \vdots & \ddots & \vdots \\ a_{n 1} & \cdots & a_{n n}\end{array}\right)_{n \times n} \cdot\left[\begin{array}{l}h_{1} \\ \vdots \\ \vdots \\ h_{n}\end{array}\right]$. 
Vejamos, para exemplificar, a matriz $A=\left(\begin{array}{ll}1 & 0 \\ 0 & 1\end{array}\right)$ que possui a forma quadrática associada $Q\left(h_{1}, h_{2}\right)=\left[\begin{array}{ll}h_{1} & h_{2}\end{array}\right] \cdot\left(\begin{array}{ll}1 & 0 \\ 0 & 1\end{array}\right) \cdot\left[\begin{array}{l}h_{1} \\ h_{2}\end{array}\right]=h_{1}^{2}+h_{2}^{2}$. Bortolossi (2009, p. 383) apresenta essa forma quadrática. Acrescentamos, todavia, seu comportamento gráfico-geométrico.

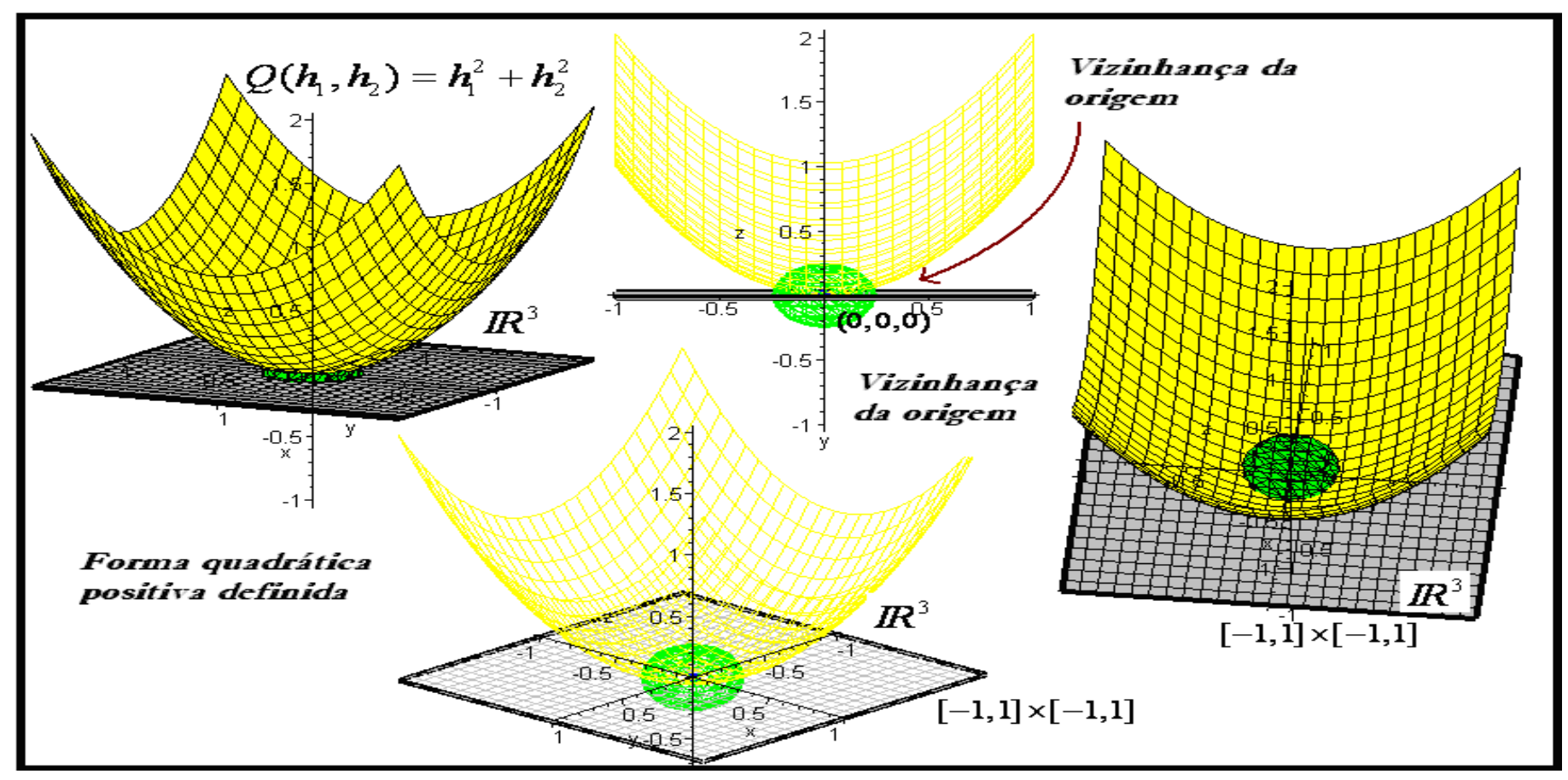

Figura 2. Gráfico da forma quadrática positiva definida no espaço $I R^{3}$

Na figura 2, indicamos uma vizinhança da origem que possibilita uma visualização local e global. Nesse caso dizemos que $A$ é uma matriz positiva definida ou que a forma $Q\left(h_{1}, h_{2}\right)=h_{1}^{2}+h_{2}^{2}$ é positiva definida. Bortolossi $\left(2009\right.$, p. 384) toma ainda a matriz $B=\left(\begin{array}{cc}-1 & 0 \\ 0 & -1\end{array}\right)$ que possui a forma quadrática associada $Q\left(h_{1}, h_{2}\right)=\left[\begin{array}{ll}h_{1} & h_{2}\end{array}\right] \cdot\left(\begin{array}{cc}-1 & 0 \\ 0 & -1\end{array}\right) \cdot\left[\begin{array}{l}h_{1} \\ h_{2}\end{array}\right]=-h_{1}^{2}-h_{2}^{2}$. E, por fim, com uma outra matriz $C=\left(\begin{array}{cc}1 & 0 \\ 0 & -1\end{array}\right)$, inferimos, do mesmo modo, que $Q\left(h_{1}, h_{2}\right)=h_{1}^{2}-h_{2}^{2}$. Na figura 2, divisamos uma bola (em cor verde) centrada na origem, de raio apropriado e, nessa vizinhança, realizamos a análise local e global de seu comportamento. 


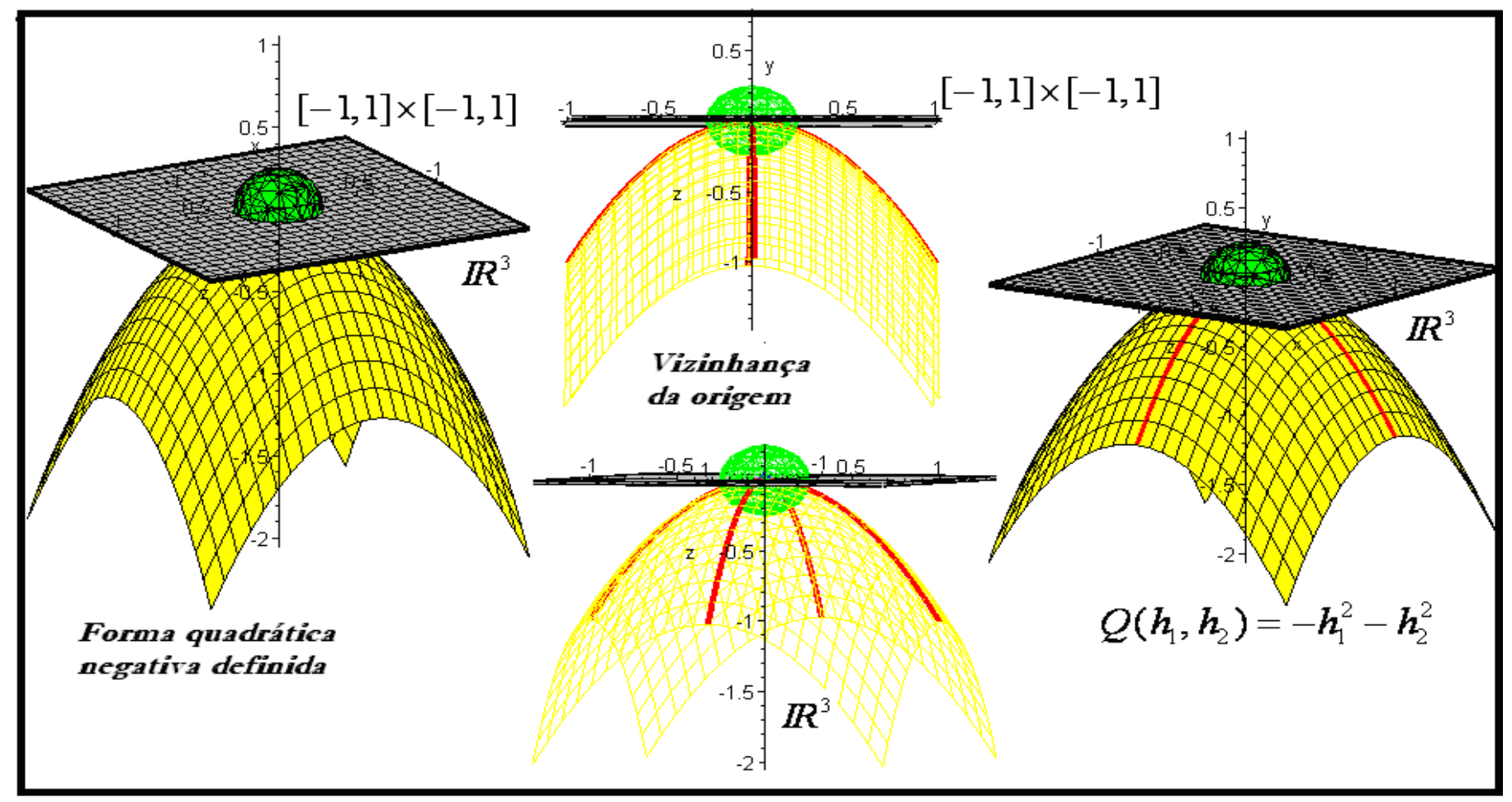

Figura 3. Gráfico da forma quadrática negativa definida no espaço $I R^{3}$ com o uso do CAS Maple

As figuras 3 e 4 nos auxiliarão para o fornecimento do significado gráfico-geométrico de uma forma quadrática negativa definida (fig. 3) e de uma forma quadrática indefinida (figura 4 abaixo). Uma vez adquirido o entendimento conceitual sobre as propriedades gráfico-visuais e matemáticas desses três figuras, procederemos a uma descrição formalista, estilo bourbaki (CHOQUET, 1963).

Assim, a forma $Q(h)=h^{T} \cdot A \cdot h>0, \forall h \neq 0$ em $I R^{n}$ é positiva definida. Dizemos também que a forma $Q(h)=h^{T} \cdot A \cdot h<0, \forall h \neq 0$ em $I R^{n}$ é negativa definida. E, por fim, a forma quadrática $Q(h)=h^{T} \cdot A \cdot h, \quad \forall h \neq 0$ em $I R^{n}$ é indefinida se existem vetores $h_{1}, h_{2} \in I R^{n}$ de modo que $Q\left(h_{1}\right)>0$ e $Q\left(h_{2}\right)<0$. As curvas parametrizadas (em vermelho) indicam a região (a vizinhança) na qual podemos encontrar $h_{1}, h_{2} \in I R^{n}$. No caso em que a matriz é a matriz hessiana, segundo Lima (2009, p. 157), podemos concluir que uma função $f \in C^{2}$, possuirá um mínimo local nãodegenerado, quando a forma é positiva. Possuirá máximo local não-degenerado quando a forma é negativa. Por fim, $f$ possuirá um ponto de sela quando a forma é indefinida. 


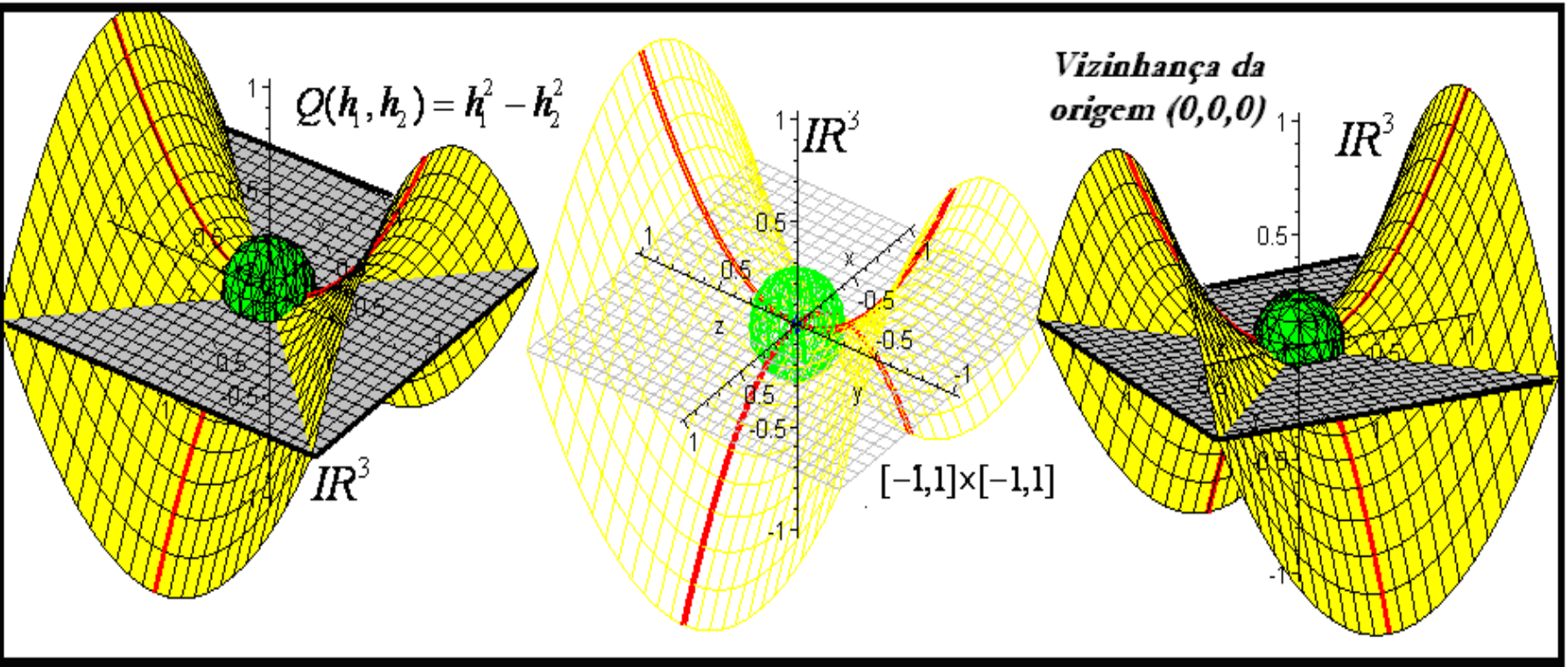

Figura 4. Gráfico da forma quadrática indefinida descrita com o uso do CAS Maple (elaboração do autor)

Para concluir essa seção, na figura 5, notamos certa mudança de cores. Tal mudança corresponde à variação numérica, para cada par $(x, y) \in I R^{2}$, de cada função. Os tons mais avermelhados indicam que a imagem da função $f(x, y)$ se aproxima da origem, com $z \rightarrow 0^{+}$, na medida em que $(x, y) \rightarrow(0,0)$ (fig. 5-I). Os tons em amarelo indicam que a mesma aproximação ocorre, entretanto, com valores simétricos (negativos). Em ambos os casos, teremos o predomínio de somente uma cor, na vizinhança do ponto $(0,0)$. Mas, no caso das curvas de nível determinadas pela forma quadrática da figura 4, ocorrem mudanças e variações de cores. Tais mudanças indicam a mudança de sinal da forma indefinida $Q\left(h_{1}, h_{2}\right)=h_{1}^{2}-h_{2}^{2}$.

De fato, no caso das figuras 5-I e 5-II, a invariância da cor é um fator qualitativo indicador que as formas quadráticas há pouco indicadas por $Q\left(h_{1}, h_{2}\right)=h_{1}^{2}+h_{2}^{2}$ e $Q\left(h_{1}, h_{2}\right)=-h_{1}^{2}-h_{2}^{2}$ não mudam de sinal (padrão que pode ser visualizado próximo da origem). Reparemos, entretanto, que o amparo computacional viabiliza a uma ação interpretativa qualitativa de noções matemáticas formais, como as que indicamos até o momento.

Podemos, agora, comparando as figuras 1 e 5, realizar ligações conceituais importantes no que se refere à natureza de um ponto crítico de uma função $f \in C^{2}$ e seu comportamento em uma vizinhança do mesmo. Por outro lado, quando restringimos nosso ensino ao estilo axiomático, formal e estruturante (CHOQUET, 1963, p. 25), que espécie de habilidade cognitiva se torna mais evidente, no campo de novas aprendizagens do indivíduo? Um algoritmo ou uma ação manipulativa de registros eminentemente analíticos transmitem sensação semelhante? 
Indicaremos, pois, alguns entraves de caráter manipulativo inerente ao estudo de formas quadráticas hessianas.

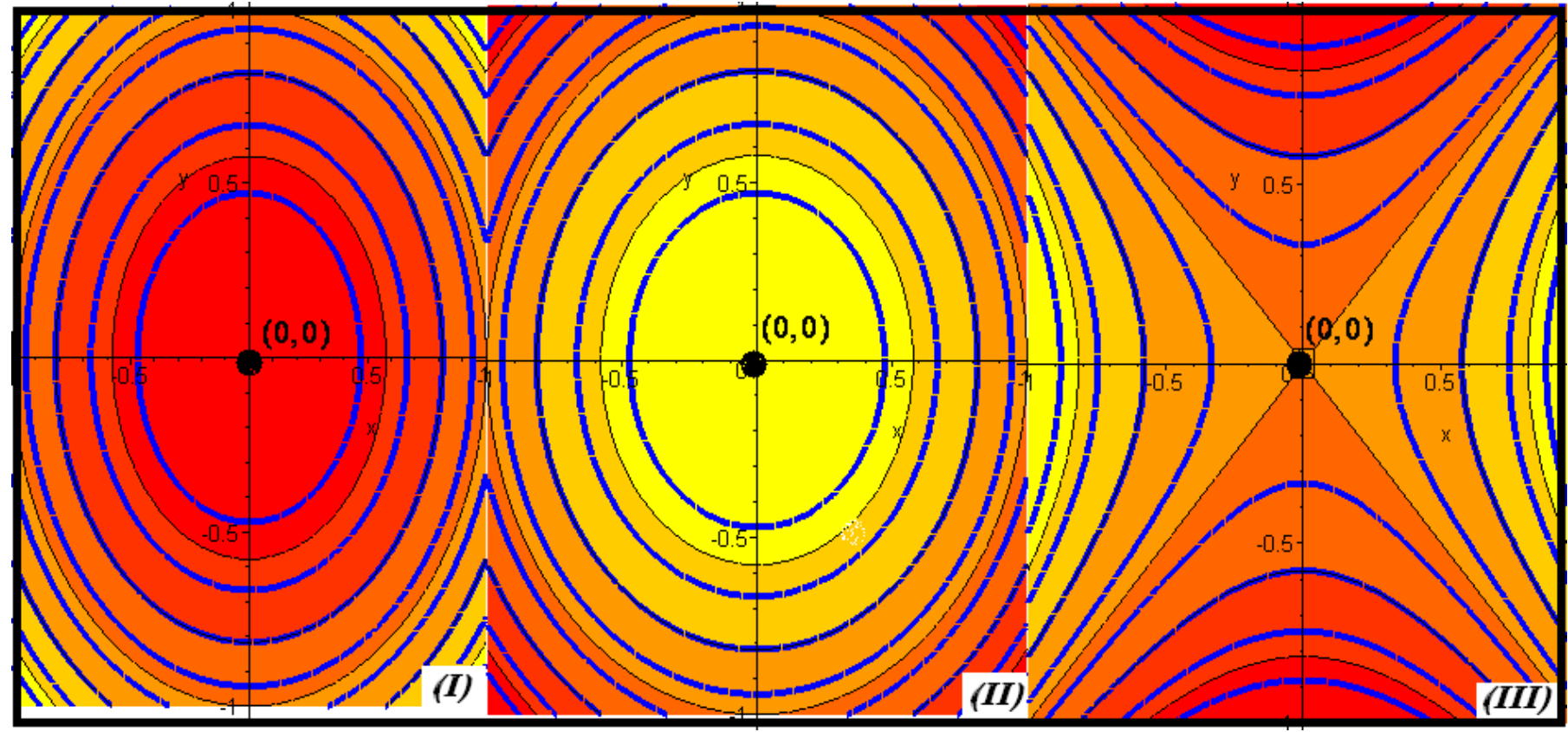

Figura 5. Descrição gráfico-geométrica das curvas de nível e o comportamento das formas quadráticas com o uso do CAS Maple (elaboração do autor)

Vejamos, pelo menos, uma resposta provisória para nosso último questionamento. Com efeito, recordamos que o trato eminentemente algébrico de formas quadráticas envolve alguns entraves. Nesse sentido, vale observar o exemplo discutido por Lima (2009, p. 159), ao considerar a seguinte forma quadrática hessiana $H(x, y, z)=3 x^{2}+2 y^{2}-5 z^{2}+4 x y+2 x z-y z$. O autor orienta a seguinte manipulação das parcelas que contém ' $x$ ' da maneira seguinte:

$3 x^{2}+4 x y+2 x z=3\left[x^{2}+2 x(2 y / 3+z / 3)\right]=3\left[(x+2 y / 3+z / 3)^{2}-(2 y / 3+z / 3)^{2}\right]=\left[3 u^{2}-1 / 3(2 y+z)^{2}\right]$

Segue que $H(x, y, z)=3 u^{2}-1 / 3(2 y+z)^{2}+2 y^{2}-5 z^{2}-y z=3 u^{2}+2 y^{2} / 3-16 z^{2} / 3-7 / 3 \cdot y z$ e, usando um raciocínio semelhante, insere a substituição $v:=y-7 z / 4$. Finalmente, descreve forma quadrática hessiana em termos das variáveis introduzidas indicada agora por $H(u, v, z)=H(u, v)=3 u^{2}+2 v^{2} / 3-177 z^{2} / 24$. 
Lima (2009, p. 159) argumenta, por fim, que $H$ é indefinida. A ilação do autor se apoia no fato de que, para $u^{2}+v^{2} \neq 0$ e $\mathrm{z}=0 \therefore H(u, v, z)>0$. E se ocorrer que $u^{2}+v^{2}=0$ e $\mathrm{z} \neq 0 \therefore H(u, v, z)<0$. Deste modo, se contamos com um ponto crítico não-degenerado, não pode existir um comportamento de máximo, pois se tem $u^{2}+v^{2} \neq 0$ e $\mathrm{z}=0 \therefore H(u, v, z)>0$. De modo análogo, não pode ocorrer um comportamento de mínimo, pois se tem $u^{2}+v^{2}=0$ e $\mathrm{z} \neq 0 \therefore H(u, v, z)<0$. Ademais, como proceder para a descrição de um vínculo conceitual entre esta análise de cunho analítico com os dados sugeridos na figura 1 ? Que imagem mental promovemos ou que elementos de cunho intuitivo são colocados em destaque nesse tipo de abordagem, eminentemente de viés estrutural e formal?

Independentemente de uma resposta definitiva, afirmamos que tal abordagem é cômoda para os experts no assunto, entretanto, por esta via, a visualização é negligenciada. Na próxima seção, a partir da indicação do uso da tecnologia, apresentaremos situações que detém a possibilidade de explorar um campo conceitual de maior abrangência, que superam os limites da lógica e da matemática.

\section{DISCUSSÃO DE OUTROS EXEMPLOS COM AMPARO NA TECNOLOGIA COM VISTAS AO ENSINO DE CÁLCULO}

Assinalamos na seção anterior que o trato algébrico fornece alguns entraves e limitações de análise, com vistas ao entendimento de um comportamento qualitativo da forma quadrática. Nessa seção, colocaremos em destaque as potencialidades dos softwares Geogebra e do CAS Maple, sob um viés de complementaridade. Com tal objetivo, adotamos, de modo preliminar, a seguinte função $z=f(x, y)=x^{3}-y^{3}+9 x y$.

De imediato $\nabla f(x, y)=\left(3 x^{2}+9 y,-3 y^{2}+9 x\right) \quad$ e, impondo a condição $\nabla f(x, y)=(0,0) \leftrightarrow(x, y)=(0,0)$ ou $(x, y)=(3,-3)$. Deste modo, a matriz hessiana é indicada por $D^{2} f(x, y)=H(x, y)=\left(\begin{array}{cc}6 x & 9 \\ 9 & -6 y\end{array}\right)$, portanto, determinamos em cada ponto as matrizes hessianas: $H_{1}(0,0)=\left(\begin{array}{ll}0 & 9 \\ 9 & 0\end{array}\right)$ e $H_{2}(3,-3)=\left(\begin{array}{cc}18 & 9 \\ 9 & 18\end{array}\right)$. 
Por conseguinte, de acordo com $\left(^{*}\right)$, obteremos que $Q_{1}(x, y)=18 x y \quad$ e $Q_{2}(x, y)=18 x^{2}+18 x y+18 y^{2}$. Vale destacar as considerações de Bortolossi (2009, p. 393) quando adverte que "analisar o sinal de $18 x^{2}+18 x y+18 y^{2}$ é mais complicado do que analisar o sinal de $18 x y .$. O autor transmite tal perspectiva ao leitor, na medida em que busca apresentar argumentos que permitam afirmar ou infirmar algo sobre a natureza de ambas as formas quadráticas $Q_{1}(x, y)$ e $Q_{2}(x, y)$. Na figura 6 , trazemos as regiões, próximas da origem, onde temos definidas as superfícies correspondentes a cada uma dessas formas $Q_{1}(x, y)$ e $Q_{2}(x, y)$, com seus respectivos gráficos no espaço $I R^{3}$.

O autor transmite tal perspectiva ao leitor, na medida em que apresenta argumentos que permitem afirmar algo sobre a natureza de ambas as formas quadráticas $Q_{1}(x, y)$ e $Q_{2}(x, y)$. Na figura 6, trazemos as regiões, próximas da origem, onde temos definidas as superfícies correspondentes a cada uma dessas formas $Q_{1}(x, y)$ e $Q_{2}(x, y)$, com seus respectivos gráficos no espaço $I R^{3}$.

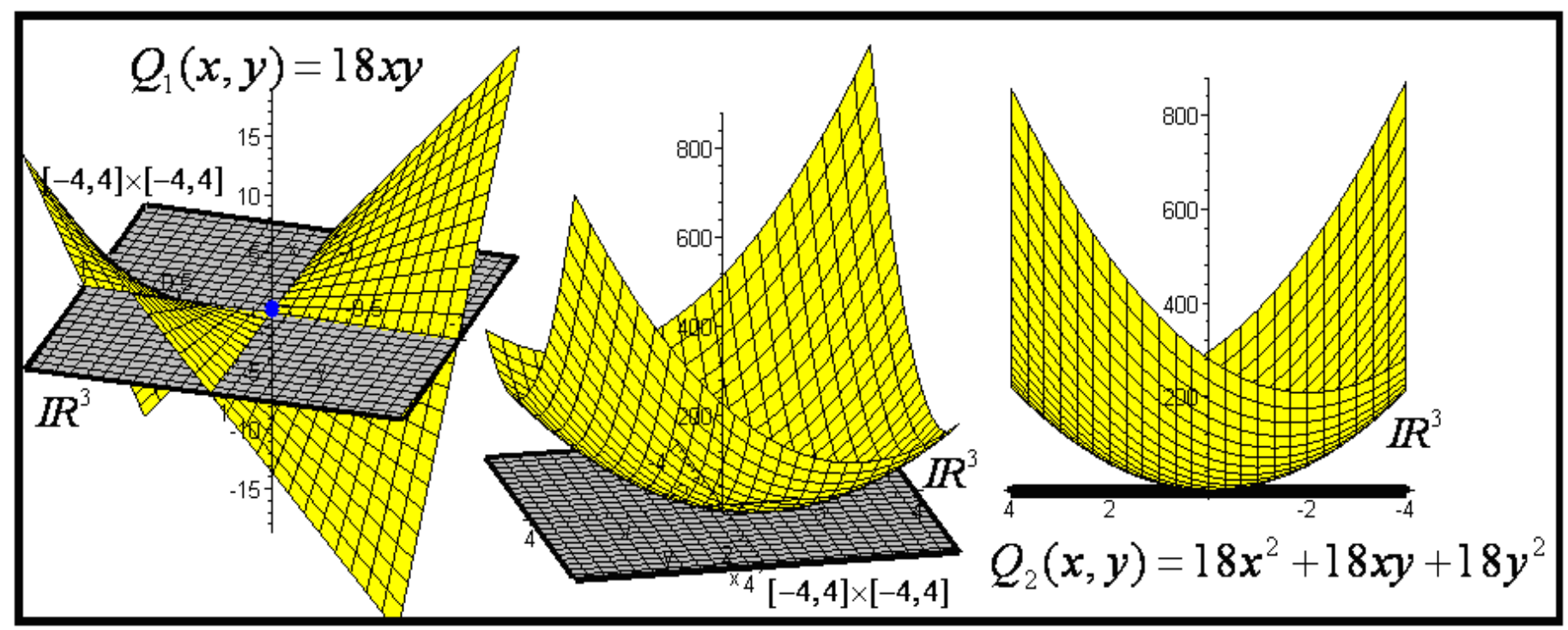

Figura 6. Análise visual do comportamento das formas quadráticas hessianas no espaço (elaboração do autor) 
Mais uma vez, a investigação do comportamento (do sinal) das formas $Q_{1}(x, y)=18 x y$ e $Q_{2}(x, y)=18 x^{2}+18 x y+18 y^{2}$ podem restringir-se ao quadro analítico-algébrico. Sob tal viés, Bortolossi (2009, p. 393) indica ainda que $Q_{2}(x, y)=18 x^{2}+18 x y+18 y^{2}=18\left[\left(x+\frac{y}{2}\right)^{2}+\frac{3}{4} y^{2}\right] \geq 0$.

Vamos, então, realizar uma análise qualitativa descritiva, comparando as figuras 6 e 7. No caso do comportamento gráfico-geométrico da figura 7, com amparo na visualização e percepção, depreendemos que ocorrem regiões, determinadas pelo plano correspondente ao conjunto compacto $[-4,4] \times[-4,4] \subset I R^{2}$, acima e abaixo, correspondente aos valores assumidos pela função $f(x, y)$ no eixo Oz.

Assim, depreendemos, com origem na percepção de propriedades topológicas locais, que a forma $Q_{1}(x, y)=18 x y$ é positiva e negativa (e que podemos associar a um ponto de sela). Em alguns pontos particulares estabelecemos $Q_{1}(1,1)=18>0, \quad Q_{1}(1,-1)=-18<0, \quad Q_{1}(-1,-1)=18>0 \quad$ e $Q_{1}(-1,1)=-18<0$. Vale, todavia, a advertência de que o registro de pelo menos dois pontos, nos quais, confirmamos a mudança de sinal da forma quadrática hessiana, é suficiente para declarar o comportamento indefinido da matriz, consequentemente, teremos um ponto de sela. Por outro lado, obter alguns pontos onde uma forma quadrática hessiana é positiva (resp. negativa), não é condição suficiente para que possamos afirmar possuir uma forma positiva definida (resp. forma negativa definida). 


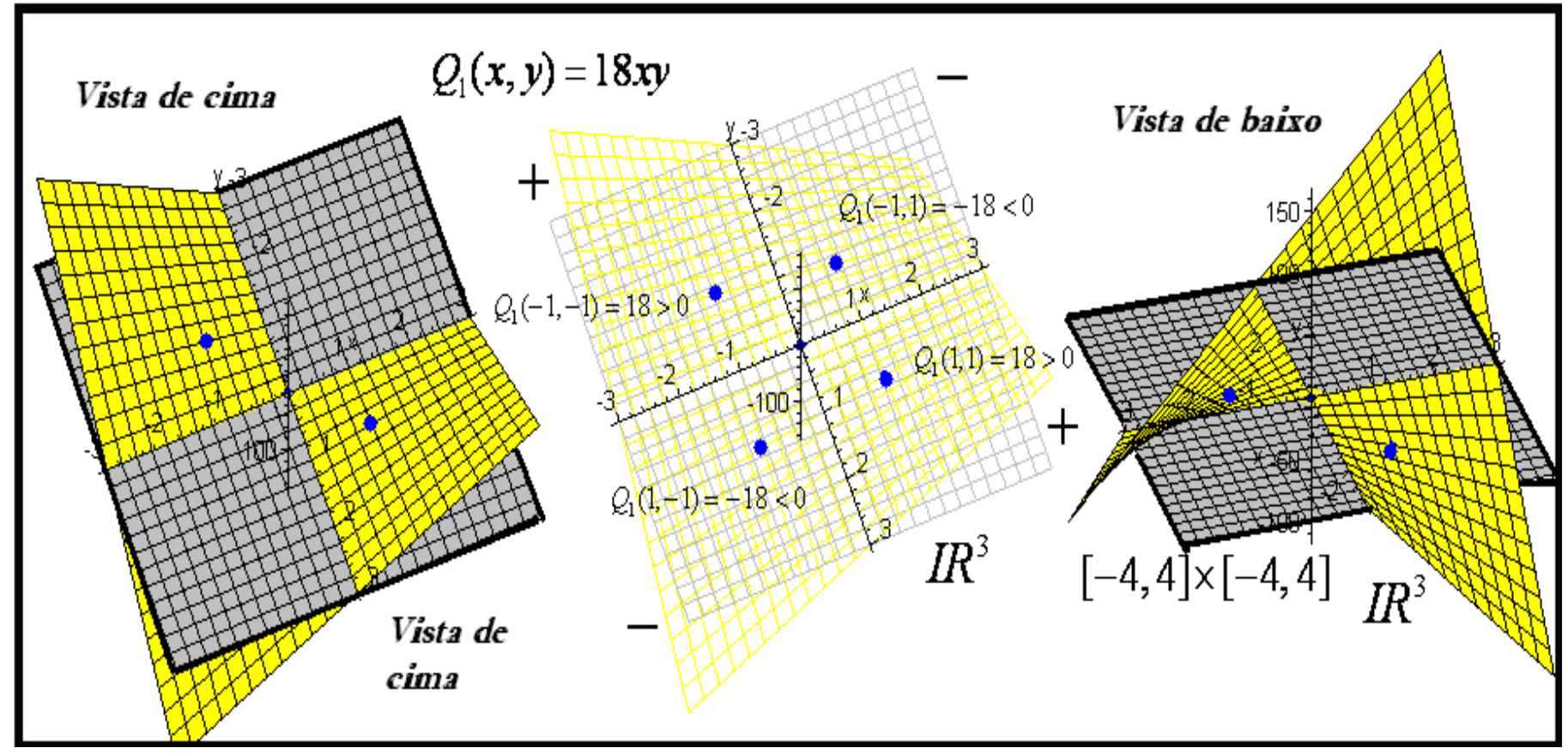

Figura 7. Identificação visual da posição dos pontos sobre a superfície correspondente à forma quadrática hessiana com o uso do CAS Maple (elaboração do autor)

Nesse cenário de incerteza, o software Geogebra pode proporcionar e viabilizar a exploração, manipulação e inspeção direta de um conjunto numérico ampliado de valores assumidos pela forma quadrática e, assim, decidir o comportamento da matriz correspondente e o entendimento do comportamento da função num ponto particular. Com este escopo, apresentamos a figura 8. Nela, identificamos a localização topológica das vizinhanças dos pontos $(0,0)$ e $(3,-3)$ no $I^{2}$. Com a definição de comandos básicos deste software, definimos os seletores "a" e " $b$ " com a variação correspondente ao compacto $(a, b) \in[-4,4] \times[-4,4]$. Descrevemos as formas quadráticas, usando a seguinte sintaxe: "=" + (18 a b) e "=" + (18 $\left.a^{2}+18 a b+18 b^{2}\right)$. 


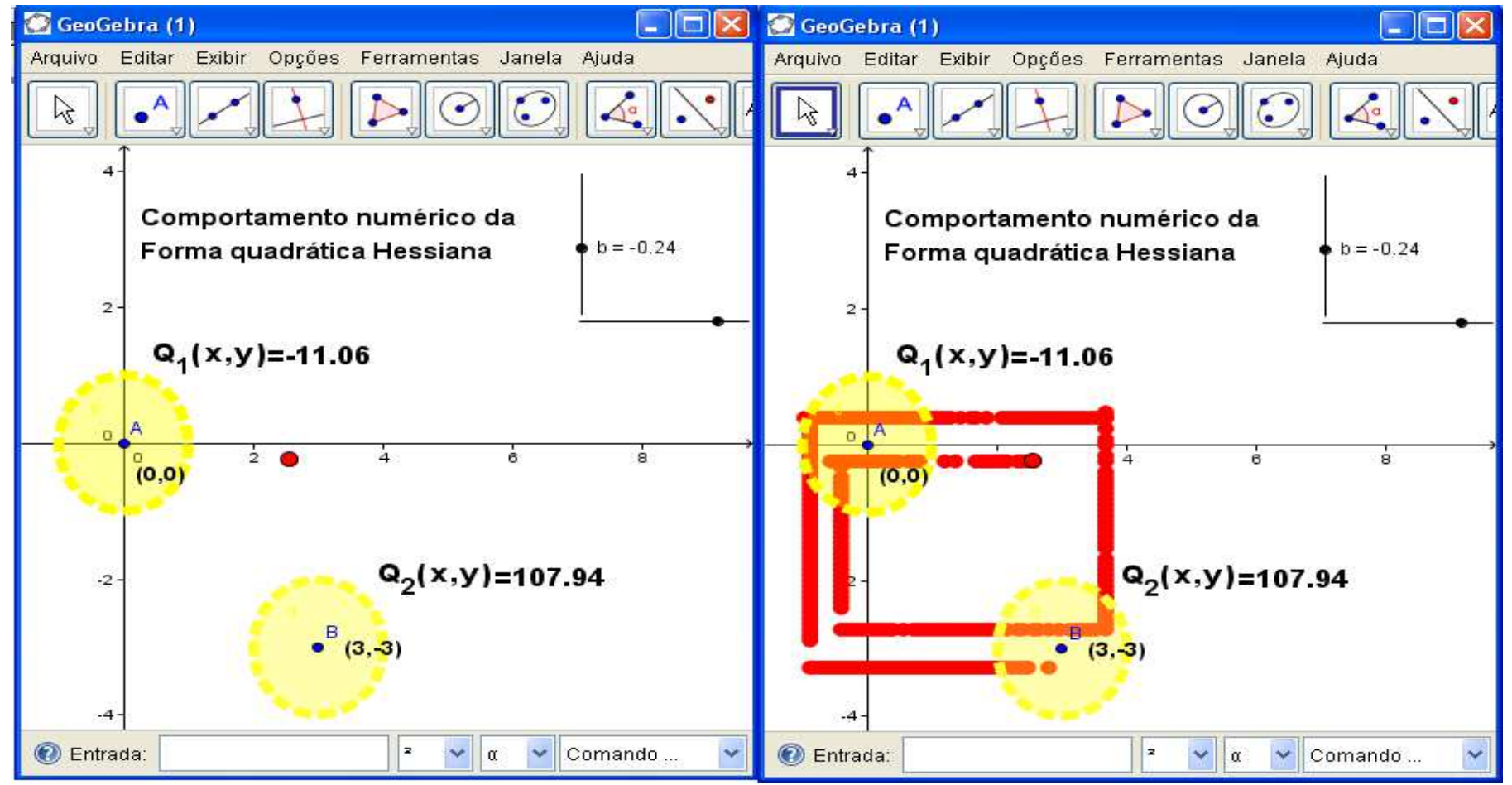

Figura 8. O software Geogebra permite inferir o comportamento numérico das formas quadráticas hessianas

O efeito esperado, após realizar alguns ajustes didáticos no sentido de preparar o cenário de aprendizagem e conduzir o aluno interagir com a propriedade que desejamos transmitir, abstraindo um entendimento conceitual, diz respeito à dinamicidade de inspeção numérica dos valores de cada forma quadrática $Q_{1}(x, y)$ e $Q_{2}(x, y)$. De fato, na figura 8 , do lado direito, divisamos o rastro (em cor vermelha) da trajetória de uma manipulação particular dos seletores no plano $I R^{2}$. Seu uso permite a aferição numérica de uma enorme quantidade de valores, com aproximação da casa decimal desejada, sempre em cada vizinhança de interesse. 0 uso do software permite romper o caráter estático e linear que patenteamos nos compêndios especializados de Cálculo, e destacar um olhar topológico e local do comportamento das formas $Q_{1}(x, y)$ e $Q_{2}(x, y)$.

Vejamos agora a função $z=f(x, y)=x^{4}+y^{4}-4 x y+1$. Agora, seu vetor gradiente é dado por $\nabla f(x, y)=\left(4 x^{3}-4 y, 4 y^{3}-4 x\right)$. Assim, impomos a condição $\nabla f(x, y)=(0,0) \Rightarrow(x, y)=(0,0)$, $(x, y)=(1,1) \quad$ e $\quad(x, y)=(-1,-1) . \quad$ A matriz hessiana é indicada por $D^{2} f(x, y)=H(x, y)=\left(\begin{array}{cc}12 x^{2} & -4 \\ -4 & 12 y^{2}\end{array}\right)$. Consequentemente, escrevemos: $H_{1}(0,0)=\left(\begin{array}{cc}0 & -4 \\ -4 & 0\end{array}\right)$, 
$H_{2}(1,1)=\left(\begin{array}{cc}12 & -4 \\ -4 & 12\end{array}\right)$ e $H_{3}(-1,-1)=\left(\begin{array}{cc}12 & -4 \\ -4 & 12\end{array}\right)$. Nesse caso, determinaremos três formas quadráticas hessianas: $Q_{1}(x, y)=-8 x y$ e $Q_{2}(x, y)=12 x^{2}-8 x y+12 y^{2}=Q_{3}(x, y)$, usando a definição indicada em (*) (seção 2).

Na figura 9, depreendemos a possível existência de três pontos críticos (não-degenerados). Dois deles (centro da figura) possuem a "aparência" de pontos extremos locais (mínimos). Enquanto que um deles (fig. 9, lado direito) se assemelha a um ponto de sela, na origem $(0,0)$. Desenvolveremos, doravante, o instrumental conceitual amparado na visualização, no sentido de ratificar nossas conjecturas. O confrontamento dos dados finais, coligidos nessa investigação é fundamental (ALVES, 2011, p. 239).

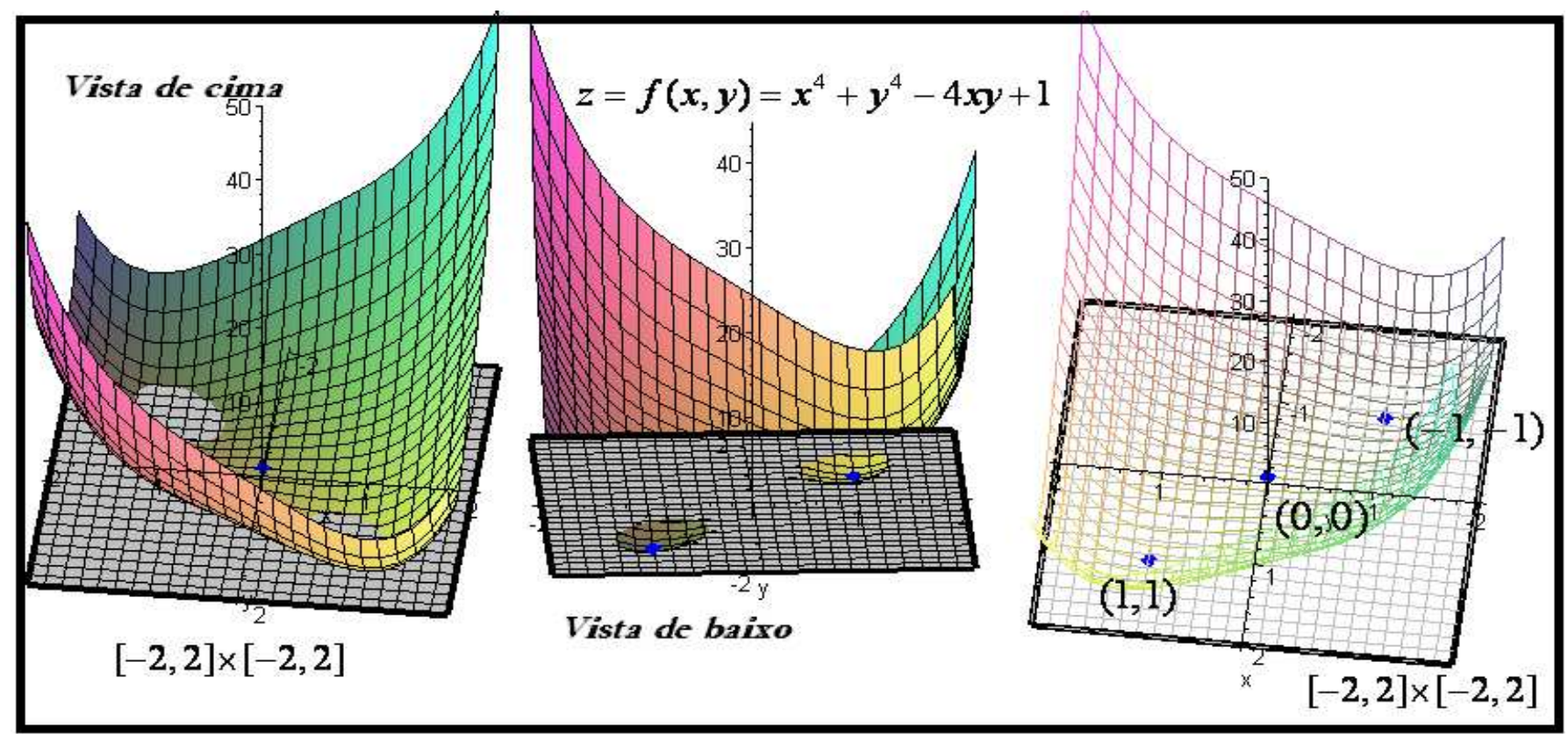

Figura 9. Visualização possibilitada pelo CAS Maple na identificação de extremantes

Vejamos que, de acordo com as indicações de Lima (2009), destacadas, no início (figura 1), mais uma vez, desconfiamos que, os pontos $(1,1)$ e $(-1,-1)$ são pontos extremantes, enquanto que na origem, possivelmente, teremos um ponto de sela (ver figura 10). Vale assinalar o caráter heurístico da fundamentação mobilizada para a obtenção de uma conclusão nesse caso particular. Todavia, o comportamento descrito e sugerido por Lima (2009, p. 287) é sempre esperado, para essas categorias de pontos críticos? 


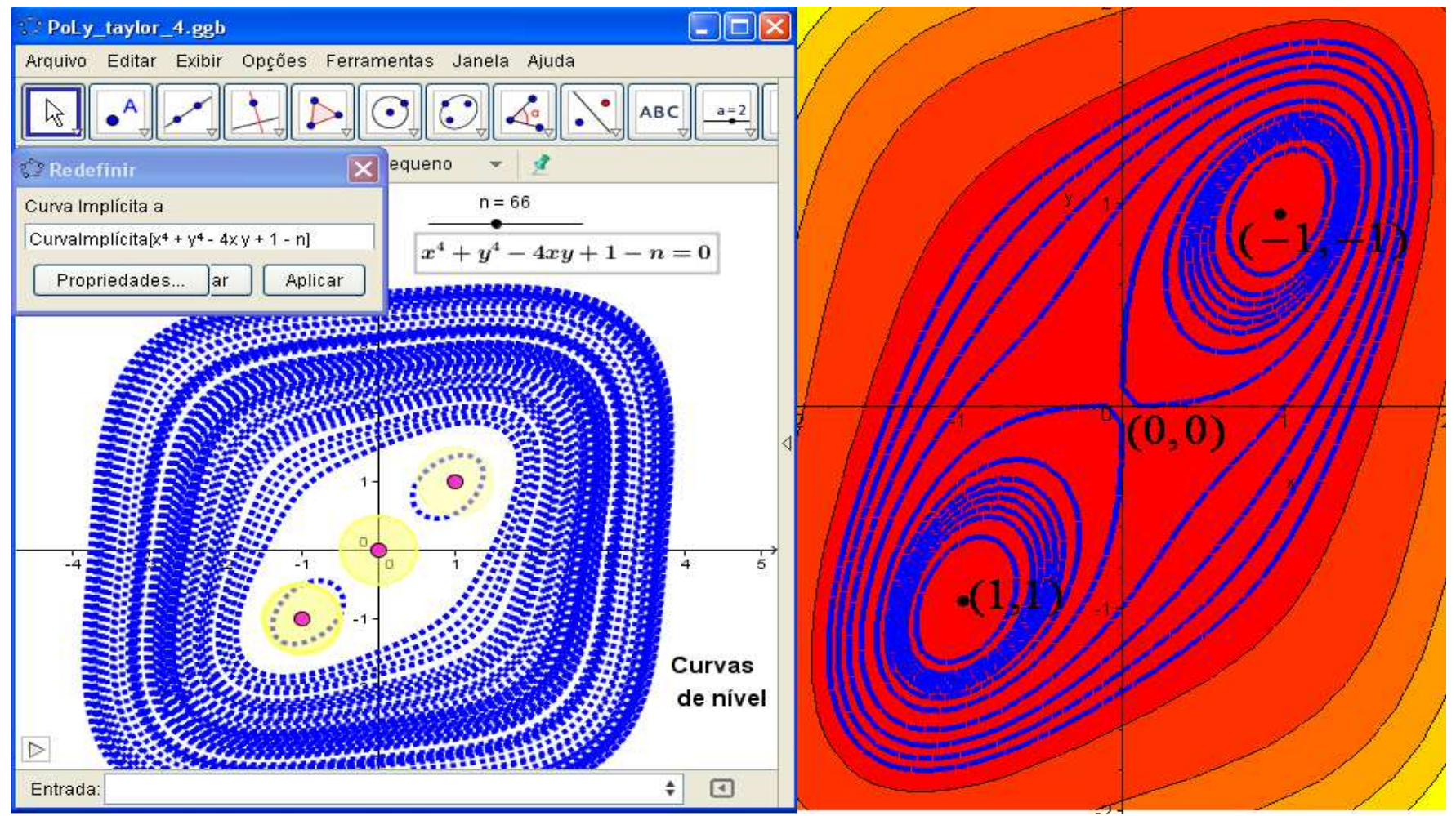

Figura 10. Descrição das curvas de nível na vizinhança de pontos críticos não-degenerados com o software Geogebra (lado esquerdo) e o CAS Maple (lado direito).

Com o uso do CAS Maple, vamos analisar o comportamento da superfície correspondente a uma das formas quadráticas hessianas descritas há pouco. Evidenciaremos que as indicações de Lima (2009, p. 287) são passíveis de algumas restrições e, mesmo, a possibilidade do acréscimo de outros padrões negligenciados por esse autor. De fato, trazemos alguns exemplos interessantes salientados em Kaplan (1993, p. 157). Assim, tomemos as funções: $f(x, y)=x^{3}-3 x y^{2}$, $g(x, y)=x^{2} y^{2}$ e $h(x, y)=4-y^{2}$.

Nesses casos, verificamos, sem ulteriores complicações, que os respectivos determinantes das matrizes hessianas de $f$ e $g$ e $h$, com respeito ao ponto $(0,0)$ são nulas, no que concerne às três funções. Daí, de acordo com a definição indicada em Lima $(2009$, p. 156), o ponto $(0,0)$ é critico degenerado com respeito às funções $f$ e $g$ e $h$.

Para esses casos, recorremos, pois, à definição de forma quadrática positiva/negativa semidefinida e a forma identicamente nula $\left(Q(h)=h^{T} \cdot A \cdot h \geq 0, \forall h \neq 0\right.$ em $I^{n}$ ou $Q(h)=h^{T} \cdot A \cdot h \leq 0$, $\forall h \neq 0$ em $\left.I R^{n}\right)$. Lima (2009, p. 159) adverte que nesses casos, nada se pode afirmar sobre a existência de máximo ou mínimo local. Vale comparar que, quando contamos com uma forma 
quadrática indefinida, na vizinhança do ponto em análise, não existem pontos de máximo e de mínimo local (BORTOLOSSI, 2008. O caráter forte, nesse caso, é a negação da possibilidade de existência de algum extremante. Reparemos que o caráter de existência é de per si uma noção complexa e que poderia ser melhor explorado pelos autores de livros de CVV.

Por outro lado, quando concluímos ter encontrado pontos críticos degenerados, o caráter de existência não é mais negado e as formas quadráticas correspondentes podem ser semidefinidas (positivas ou negativas) (BORTOLOSSI, 2008, p. 384-385). De fato, com respeito à função $f(x, y)=x^{3}-3 x y^{2}$, que possui a forma quadrática $Q(x, y) \equiv 0$, tendo o ponto $(0,0)$ crítico degenerado. A existência de um ponto de sela, com multiplicidade maior do que um, é observada (lado esquerdo). E, quando comparamos as figuras 11 e 12, adquirimos um entendimento sobre a natureza do ponto de sela (lado esquerdo).

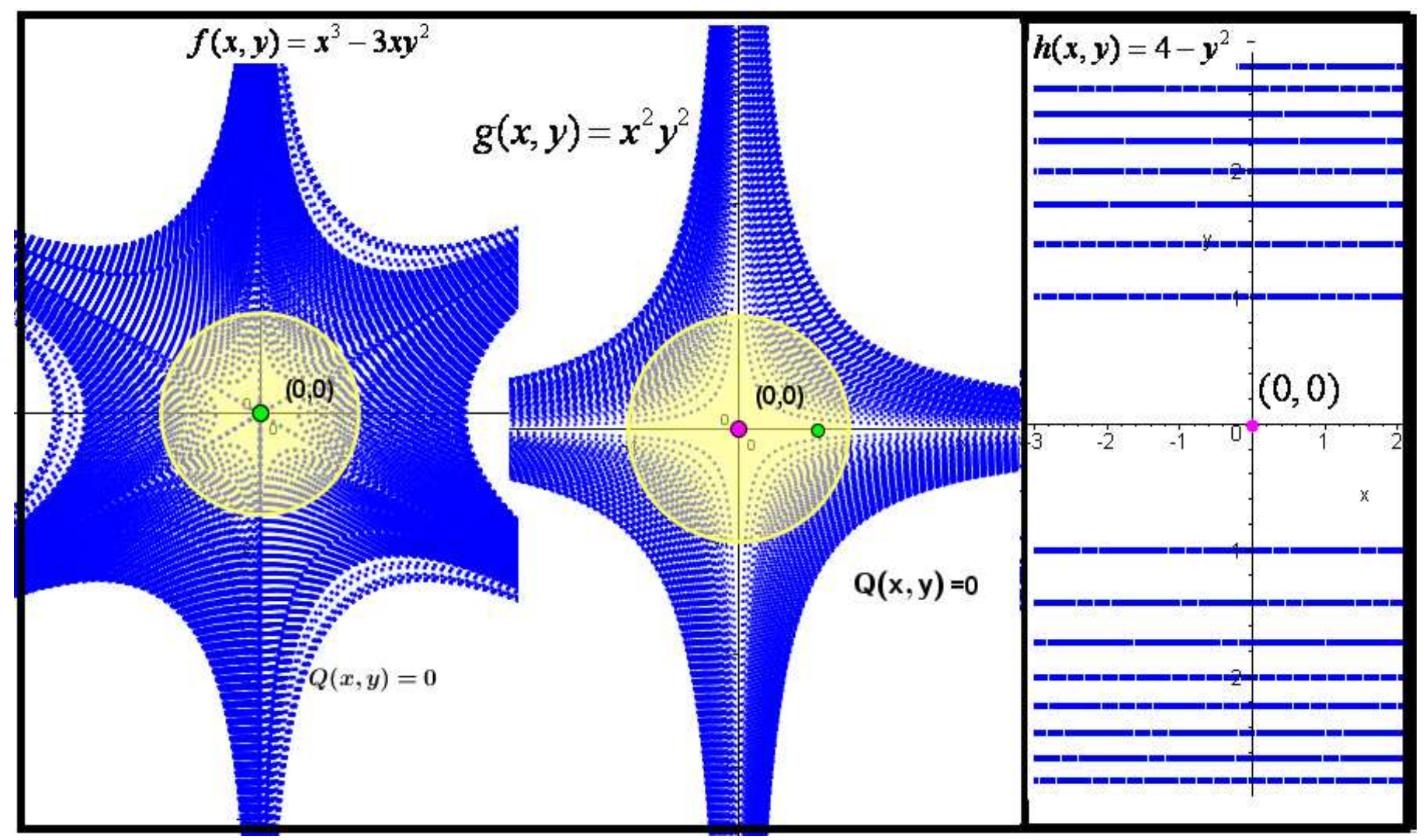

Figura 11. Descrição das curvas de nível nas vizinhanças de pontos críticos degenerados e verificação do comportamento das curvas de nível com o uso do software Geogebra e o CAS Maple

A função $g(x, y)=x^{2} y^{2}$, cuja forma quadrática é $Q(x, y) \equiv 0$ e apresenta, todavia, um ponto de mínimo local (figura 12), embora tenhamos, aqui, outro ponto crítico degenerado. Observamos 
nos dois primeiros casos que as curvas de nível, nas vizinhanças da origem, se assemelham a hipérboles (curvas abertas). Por fim, sem um apoio de uma análise mais substancial, de modo tácito, divisamos um ponto de máximo local (fig. 12, lado direito), correspondentemente a função $h(x, y)=4-y^{2}$. Com já assinalamos, sua matriz hessiana é $H(x, y)=\left(\begin{array}{cc}0 & 0 \\ 0 & -2\end{array}\right), \forall(\mathrm{x}, \mathrm{y}) \in \mathrm{IR}^{2}$ com determinante nulo. Assim, sua forma quadrática negativa semidefinida é descrita pela expressão $Q(x, y)=-2 y^{2}$. Os padrões gráfico-geométricos correspondentes a estes pontos críticos degenerados em 11 poderiam ampliar a classificação/descrição prevista por Lima (2009, p. 287).

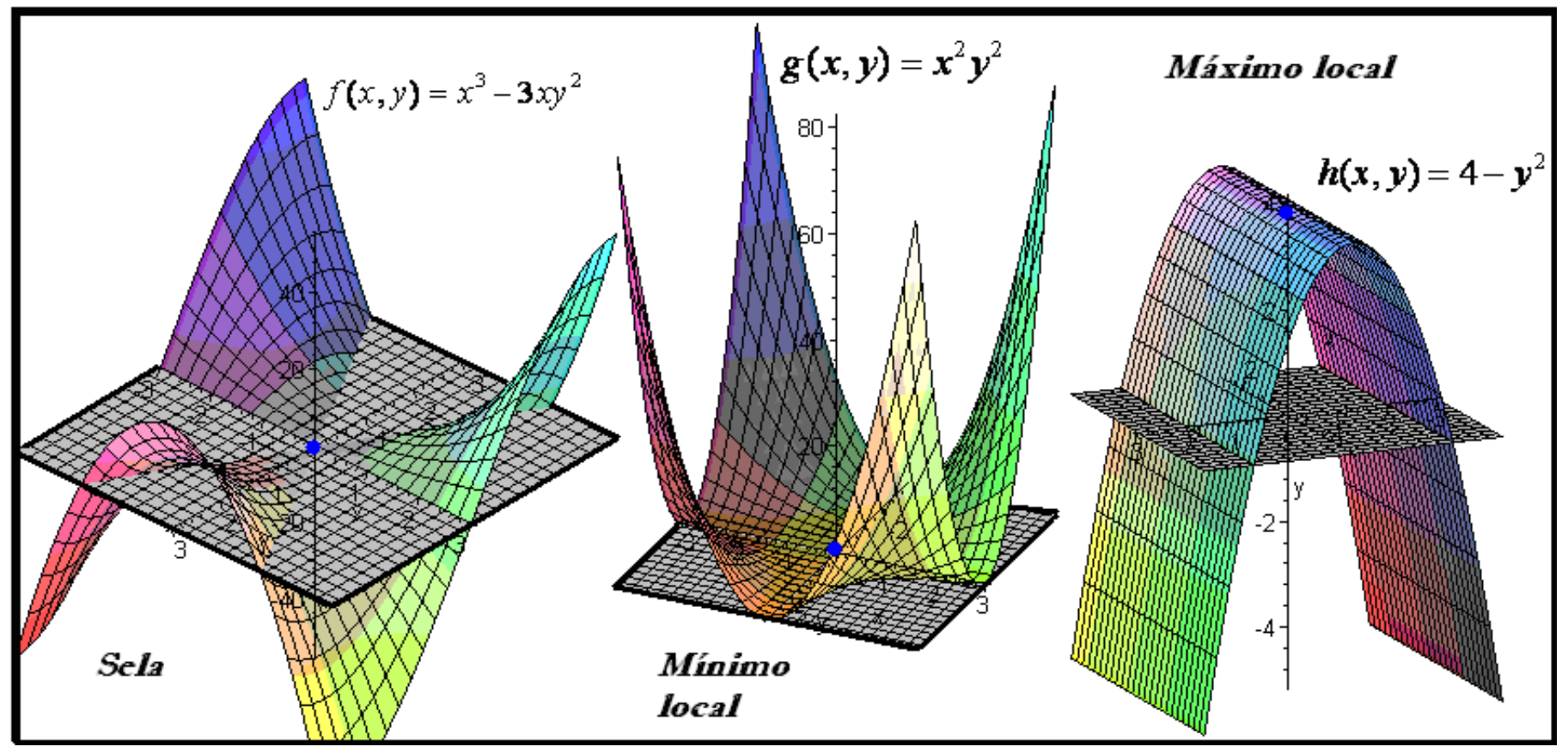

Figura 12. Descrição das superfícies nas vizinhanças de pontos críticos degenerados em $(0,0)$ com o uso do CAS Maple (elaboração do autor) 


\section{TÉCNICA COMPUTACIONAL PARA O ENSINO DE MATEMÁTICA - $C T^{2} M$}

Nas seções anteriores, trouxemos alguns exemplos que envolvem o trato e a mediação da noção de pontos extremantes de funções. O elemento invariante, relativo à cada situação problema, diz respeito ao potencial de visualização e a interpretação qualitativa do objeto pretendido, na condição em que exploramos a tecnologia atual. E, em nosso caso, exploramos, e indicamos, elementos que se mostram inexequíveis de se tornarem elementos de uma análise, tendo em vista um entendimento heurístico de cada problema. Ademais, em cada caso, apontamos/registramos o modelo matemático formal sobre o qual assentamos e fundamentamos todas as ilações produzidas nas seções anteriores. Sem perder de vista nosso principal objetivo que se refere ao ensino de formas quadráticas e à identificação de pontos extremantes, apoiados na visualização de conceitos acadêmicos, indicamos/sistematizamos os seguintes aspectos:

(i) determinada teoria formal que possibilita o emprego de técnicas e/ou algoritmos extensos que exigem o uso de um CAS; (ii) certas construções gráfico-geométricas que permitem a exploração do movimento e da dinamicidade dos objetos em questão; (iii) dado à natureza intrínseca dos objetos e suas respectivas representações 2D ou 3D, empregamos um CAS; (iv) o uso de dois softwares possibilita situações do tipo $2 D \rightarrow 3 D$; (v) o uso de dois softwares possibilita situações do tipo $2 D \rightarrow 3 D$; (vi) com o uso da tecnologia impulsionamos a apreensão perceptual de propriedades matemáticas reconhecidamente intrincadas (ALVES, 2014c).

Esses elementos permeiam/guiam todas as ações executadas nas seções anteriores, que envolvem grande preocupação com a visualização, a apreensão perceptual e o entendimento tácito e primário de conceitos complexos (ALVES, 2013) por parte dos aprendentes. Destarte, podemos proporcionar um cenário de aprendizagem, cujo elemento inicial e impulsionador da compreensão do aluno reside na intuição, e não apenas no raciocínio formal cifrado matemático.

Como indicamos nas seções anteriores, o trato eminentemente algébrico desse conteúdo garante a validade e a consistência das inferências mobilizadas, conquanto não sustenta, seguramente, um aprendizado e entendimento heurístico de cada situação (ALVES, 2014b). 


\section{CONSIDERAÇÕES FINAIS}

A identificação de pontos extremantes de funções em várias variáveis constitui interesse de matemáticos, registrado há séculos, em livros de História da Matemática (BOTTAZINNI, 1986; HAIRER \& WANNER, 2008; THIKOMIROV, 1990). Atualmente, as obras trazem, de modo standard, duas formas de desenvolver um instrumental teórico-conceitual, que permite inferir sua existência ou a sua inexistência, bem como o comportamento local de vizinhanças em pontos extremantes.

Na medida em que exploramos a tecnologia, mostramos que o desenvolvimento de Taylor até $2^{2}$ ordem sugere a definição de uma forma quadrática hessiana e, a possibilidade de sua análise, não apenas de cunho analítico, mas, sobretudo, gráfico-geométrico, no plano e no espaço $I R^{3}$. Para a efetivação e elaboração de um cenário que estimula e visualização e a percepção de propriedades qualitativas vinculadas ao entendimento dessas formas quadráticas particulares, empregamos, sob um viés de complementaridade (ALVES, 2013a; 2013b; 2014a; 2014b), os softwares Geogebra e o CAS Maple (previsto pelo $C T^{2} M$ ).

Ademais, podemos agora pensar em termos de padrões gráficos-geométricos relativos ao comportamento de pontos críticos não-degenerados (fig. 1) e, também, pontos críticos degenerados (figuras 11 e 12). Relacioná-los, ainda, com a natureza do comportamento da função no ponto e a existência ou não de pontos extremantes. Cabe observar um argumento formal que garante que, nas vizinhanças dos pontos não-degenerados, em virtude do Teorema de Morse (LIMA, 2009, p. 283-284), "podemos tomar um sistema de coordenadas em relação ao qual $f$ se exprime como uma forma quadrática". Com origem neste teorema, garantimos o padrão da curvas de nível da figura 13, para pontos não-degenerados. Outrossim, o comportamento local de parte das funções que estudamos aqui é dado por intermédio de formas quadráticas.

Acrescemos, pois, a descrição das curvas de nível, no caso de ponto degenerados (que correspondem às matrizes hessianas cujo determinante é nulo). A descrição que propomos na figura 13, que acentua o comportamento das curvas de nível, constitui um caráter negligenciado pelos autores de livros de CVV, que priorizam o estilo de abordagem algorítmica na discussão deste tópico. Uma mediação didática que visa envidar os esforços no sentido de promover não apenas o 
conhecimento lógico-formal dos aprendizes, como também, os conhecimentos intuitivos e as habilidades de visualização, não podem prescindir da tecnologia (TALL, 1992; 1996).

Na figura 13, quando divisamos curvas abertas, que se assemelham a uma reta, na vizinhança de um ponto critico não-degenerado, podem ocorrer máximo ou mínimo local. Entretanto, para a categoria de pontos degenerados, quando visualizamos curvas abertas que se assemelham à hipérboles, pode ocorrer um ponto de máximo ou mínimo local, ou ainda, possivelmente, um ponto de sela. Os padrões indicados abaixo poderão servir como guia ao pensamento inicial dos estudantes no estudo deste tópico no locus acadêmico.

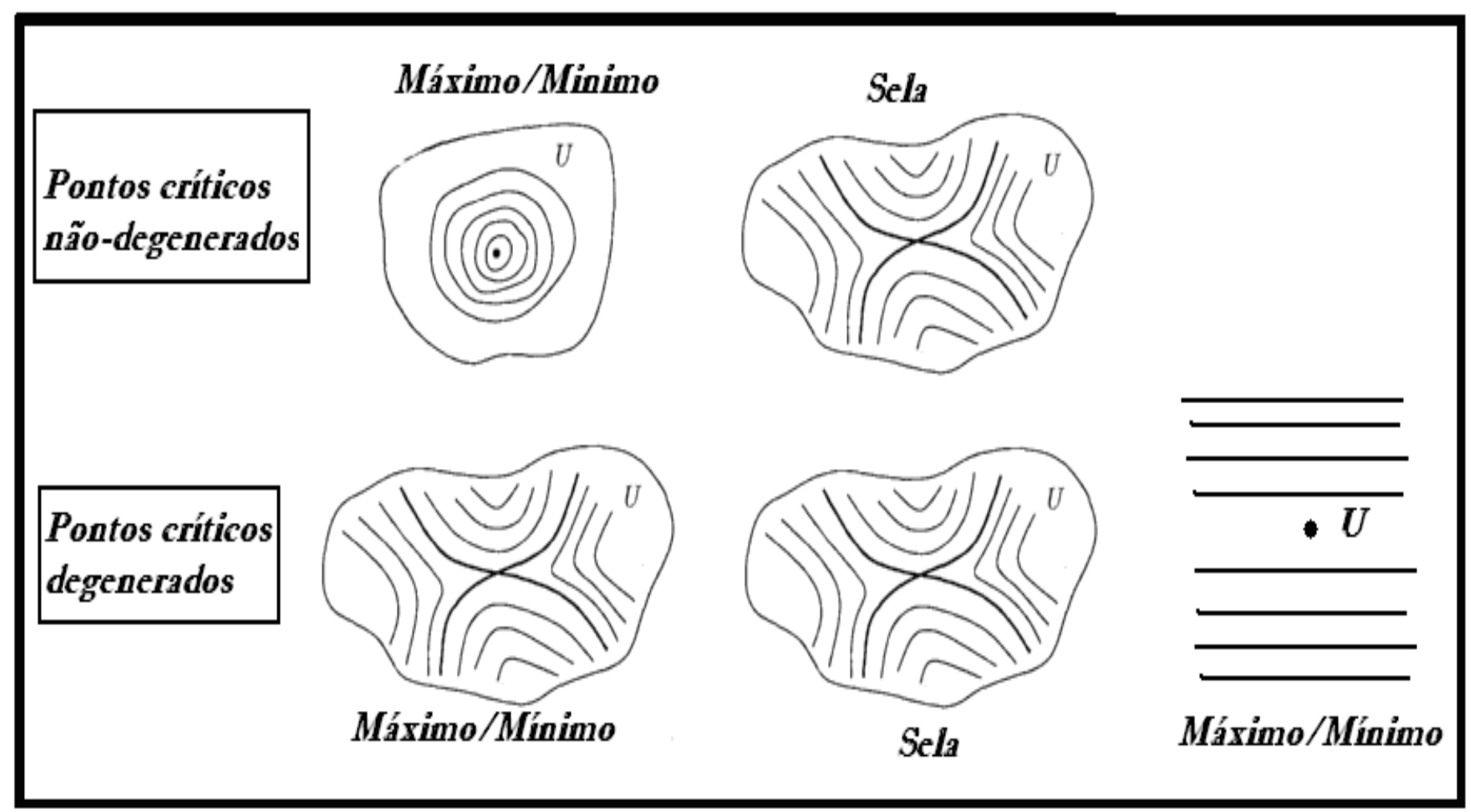

Figura 13. Descrição heurística das curvas de nível na vizinhança de um ponto crítico não-degenerado e ponto crítico degenerado (elaboração do autor)

Por fim, salientamos ainda que o esforço didático, extrassala, com o escopo de proporcionar situações semelhantes às quais discutimos aqui, não exige aprofundado conhecimento de linguagem de programação computacional do professor e/ou matemático profissional (ALVES \& BORGES NETO, 2012). Outrossim, seu uso condiciona uma transposição didática (CHEVALLARD, 
1991) diferenciada para o ensino Cálculo, reconhecido em diversos países, por especialistas, como demasiadamente formal e rigoroso (ARTIGUE, 1995).

\section{REFERÊNCIAS}

ALVES, Francisco. R. V. Aplicações da Sequência Fedathi na promoção das categorias do raciocínio intuitivo no Cálculo a Várias Variáveis. Fortaleza: UFC, 2011, 399 p. Tese (Doutorado) - Programa de Pós-graduação em Educação Brasileira, Universidade Federal do Ceará, Fortaleza, 399f.

ALVES, Francisco. R. V. Transição Interna do Cálculo: uma discussão do uso do Geogebra no contexto do Cálculo a Várias Variáveis. In: Revista do Instituto Geogebra Internacional de São Paulo. v. 1, no 2, 2013a, p. 51-19.

ALVES, Francisco. R. V. Viewing the roots of polynomial functions in complex variable: the use of Geogebra and the CAS Maple. Acta Didactica Naposcencia. Romania, v, 6, no 3, 58-45, 2013b.

ALVES, Francisco. R. V. \& Borges Neto, Hermínio. Aplicação e exploração da tecnologia no ensino do Cálculo: os softwares Geogebra e o CAS Maple. In: Anais da VI BIENAL da Sociedade Brasileira de Matemática, Campinas, 2012, p. 1-12. Disponível em: http://bienaldematematica.org.br/node/4725. Acesso em: 14 de maio 2013.

ALVES, F. R. V. Computational Tecnhique for Teaching Mathematics - $C T^{2} M$ : o caso das curvas parametrizadas. Boletim de Educação Matemática, v. 2, no 2, p. 56-71, 2014a. Disponível em: http://revistas.udesc.br/index.php/boem/issue/current/showToc

ALVES, Francisco. R. V. Visualizing Bezier's curves: some applications of Dynamic System Geogebra. Geogebra International Journal of Romania, v. 3, no 2, p. 57-68, 2014b. Disponível em: http://ggijro.wordpress.com/issues/vol-3-no-2/

ALVES, Francisco. R. V. Engenharia Didática para o Teorema da Função Implícita: análises preliminares e análise a priori. Revista Brasileira de Ensino de Ciência e Tecnologia. v. 7, no 3, 148 168. 2014c. Disponível em: https://periodicos.utfpr.edu.br/rbect/issue/view/179

ARTIGUE, M. La enseñanza de los princípios del Cálculo: problemas epistemológicos, cognitivos e didáticos. In: Artigue, M.; Douady, R. \& Gomez, L. (Ed.) Ingeniaria didactica en Educación Matemática. México: Grupo Ed. 1995, p. 97-140.

BOTTAZINI, Umberto. The Higher Calculus: a history of real and complex analysis from Euler to Weierstrass. New York: Springer, 1986.

BORTOLOSSI, H. Cálculo Diferencial a Várias Variáveis. Rio de Janeiro: Editora PUC/RJ, 2009.

CHEVALLARD, Y. La Transposition Didactique: Du Savoir Savant au Savoir Enseigné. Grenoble, La pensée Sauvage, 1991.

CHOQUET, Gustave. What is Mathematics. England: Educational Exploring Limiting Reading. 1963.

LIMA, Elon. L. Curso de Análise. v. 2, Rio de Janeiro: SBM, 2009.

GUIDORIZZI, H. Um curso de Cálculo, vol.2, Rio de Janeiro: Livros Técnicos e Científicos, 2010. 
HAIRER, E.; WANNER, G. Analysis by Its History, New York: Springer, 2008.

KAPLAN, W. Advanced Calculus. New York: Addison-Wesley, 1993.

MARSDEN, Jerrold; TROMBA, Anthony. Vector Calculus. New York: Freeman and Company, 1981.

PINTO, Diomara; MORGADO, M. Cândida. F. Cálculo Diferencial e Integral de Funções de Várias Variáveis. 3ạ edição. Rio de Janeiro: Editora UFRJ, 2009.

TALL, David. Visualizing Differentials in Two and Three Dimensions. In: Teaching Mathematics and its Applications, $11 \quad 1$, p. 1-7, 1992. Disponível em: http://homepages.warwick.ac.uk/staff/David.Tall/pdfs/dot1992b-diffls-in-2d-3d.pdf. Acesso em: 15 de junho. 2013.

TALL, David. Advanced Mathematical Thinking \& The Computer. In: Proceedings of the $20^{\text {th }}$ University Mathematics Teaching Conference. p. 1-8, 1996. Disponível em: http://homepages.warwick.ac.uk/staff/David.Tall/pdfs/dot1996a-amt-computer-umtc.pdf. Acesso em: 15 de junho. 2013.

TIKHOMIROV, V. M. Stories about Maxima and Minima. New York: American Mathematical Society. 1990.

STEWART, J. Cálculo, v. 2, 4a edição, São Paulo: Pioneira Thompson Learning, 2004.

SWOKOWSKI, Earl. W. Calculus with Analytic Geometry. Boston: Prindle, Weber e Schmidt, 1983.

WIDER, D. Advanced Calculus. New York: Prentice Hall, 1947. 